UNIVERSIDADE DE SÃO PAULO

ESCOLA DE EDUCAÇÃO FÍSICA E ESPORTE

EFEITO DO TREINAMENTO NA PLATAFORMA VIBRATÓRIA NO DESEMPENHO DE FORÇA E POTÊNCIA MUSCULAR E EM TESTES

FUNCIONAIS EM IDOSOS

Renata Gonçalves da Silva

SÃO PAULO

2008 


\section{EFEITO DO TREINAMENTO NA PLATAFORMA VIBRATÓRIA NO DESEMPENHO DE FORÇA E POTÊNCIA MUSCULAR E EM TESTES FUNCIONAIS EM IDOSOS}

RENATA GONÇALVES DA SILVA

Dissertação apresentada à Escola de Educação Física e Esporte da Universidade de São Paulo, como requisito parcial para obtenção do grau de Mestre em Educação Física. 
Da Silva, Renata Gonçalves

Efeito do treinamento na plataforma vibratória no desempenho de força e potência muscular e em testes funcionais em idosos / Renata Gonçalves da Silva. - São Paulo : [s.n.], 2008.

$$
\text { vi, 30p. }
$$

Dissertação (Mestrado) - Escola de Educação Física e Esporte da Unniversidade de São Paulo.

Orientador: Prof.Dr. Carlos Ugrinowitsch.

$\begin{array}{lll}\text { 1. Treinamento físico } & 2 . \text { Idosos } & \text { I. Título. }\end{array}$ 


\section{DEDICATÓRIA}

Gostaria de dedicar esse trabalho aos meus pais, José Eurico da Silva e Maria Isabel G Silva (in memorian) por tudo o que representam na minha vida, pelo exemplo de caráter e de vida que sempre me deram. Vocês serão sempre os meus melhores mestres. E não posso deixar de dizer que vocês são os melhores pais do mundo. Amo muito vocês.

Ao meu marido, José Carlos da Silva, meu principal alicerce. Obrigada pela paciência, dedicação e principalmente pelo amor que me dedicou durante esse período, difícil e também, maravilhoso que passamos juntos. Amo-te muito.

E em especial aos meus filhos, Mel Gonçalves Silva e Athos Gonçalves Silva, que me fizeram descobrir o real valor da vida. Vocês são os responsáveis pelos melhores momentos da minha vida. Voltar ao tempo, cantar canções de ninar, ouvir músicas infantis e relembrar contos de fadas, voltar a acreditar em papai Noel, coelho de páscoa e conto de fadas... o universo infantil...pureza, amor, sinceridade e uma alegria contagiantes. Mel: "você sabia que eu te amo?" e Athos eu também te amo muito. 


\section{AGRADECIMENTOS}

Gostaria de agradecer ao professor Doutor Carlos Ugrinowitsch pela orientação, valorosa contribuição e, principalmente, pela paciência que teve durante esse "árduo" processo.

Aos professores doutores João Fernando Laurito Gagliardi e Fernando R. de Oliveira, que são na verdade, os grandes responsáveis por esse caminho que estou trilhando. Vocês serão meus eternos professores.

Ao professor doutor Valmor Trícoli por suas contribuições intelectuais desde o início do meu ingresso no GEPAN.

A professora Rosana Andreotti e professora doutora Suely dos Santos que me ajudaram na seleção e organização dos idosos que fizeram parte desse estudo; a Paula, pela ajuda na coleta dos dados e durante os treinamentos

Aos idosos que participaram desse estudo, sempre com muito bom humor e disposição, e principalmente com grandes histórias de vida, coisas que só mesmo tempo é capaz de nos ensinar.

Ao Dr. Renato Lotufo, Dr. Moisés Cohen, do Instituto Cohen/IAFE, que nos cederam o aparelho isocinético para as avaliações e ao Felipe Machado pelo auxílio, não só na coleta dos dados, como também pelas sugestões que foram de grande importância para o projeto.

Aos amigos Flávio, Adriano, e Rômulo que sempre estavam disponíveis, não só durante a elaboração do projeto, mas desde quando comecei a pensar em ingressar na área de pesquisa.

Ao pessoal do GEPAN, em especial ao Mauro Batista e a Lilian Wallerstein.

Ao Edson Degaki, do LADESP, pelo seu auxílio, e por me "socorrer" em alguns momentos, de "desespero", dentro do laboratório.

À Lourdes, a Ilza e ao Márcio da Secretaria de Pós Graduação da EEFE-USP, que sempre me atenderam atenciosamente.

À bibliotecária Lúcia, que sempre me atendeu prontamente.

À minha família, especialmente, meu pai e minha mãe (in memorian), dotados de imensa sabedoria; às minhas irmãs, meus cunhados e cunhadas, meus sobrinhos e sobrinhas maravilhosos. Ao meu marido, José Carlos, que sempre me apoiou e me acalmou nos 
momentos que mais precisei. A meus filhos, que precisaram dividir seu tempo com artigos e computadores e sempre me recebem com um imenso sorriso nos lábios.

À minha, porque não, segunda família (em especial a Dona Benedita "vovó ditinha", a Tianinha e a Tia Iria) que me receberam com muito carinho e que sempre estiveram disponíveis nos momentos em que mais precisei. 


\section{SUMÁRIO}

Página

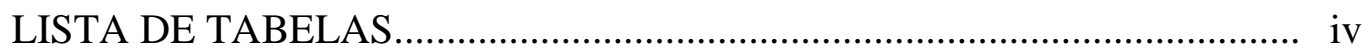

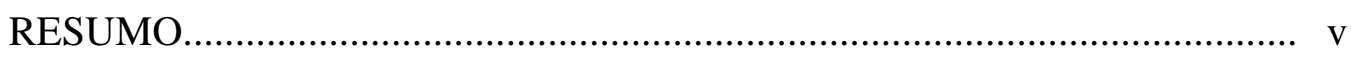

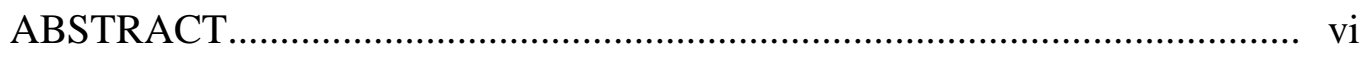

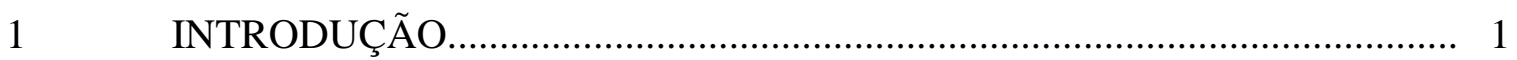

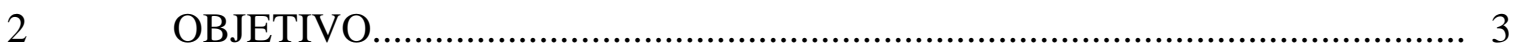

3 REVISÃO DA LITERATURA

3.1 Alterações durante o processo de envelhecimento.......................................... 3

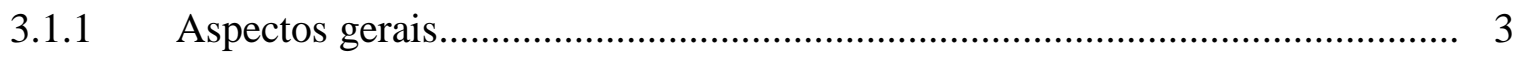

3.1.2 Características musculares................................................................... 4

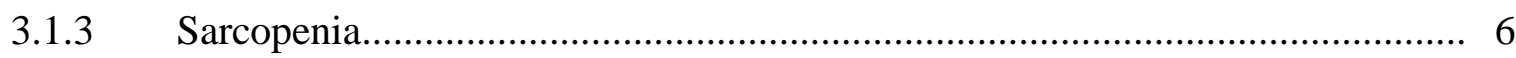

3.2 Execução das AVD’s e a perda funcional em idosos..................................... 7

3.3 Treinamento de vibração..................................................................... 8

3.3.1 Mecanismos fisiológicos que explicam os efeitos da vibração......................... 9

3.3.2 Tempo de manifestação dos efeitos da vibração............................................. 10

3.3.3 Efeitos do treinamento de vibração em idosos.............................................. 11

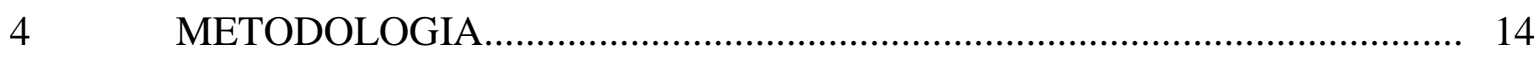

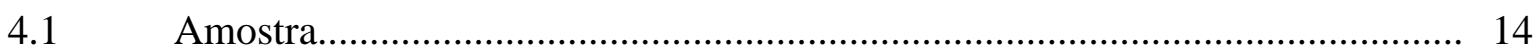

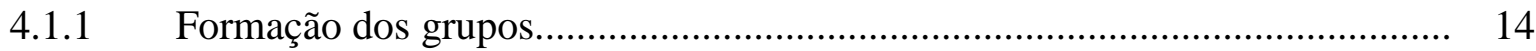

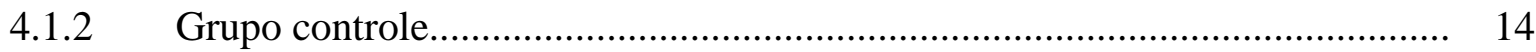



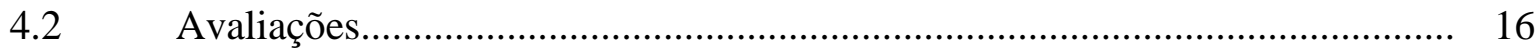

4.2.1 Medidas antropométricas (estatura, massa corporal e imc)........................... 16

4.2.2 Flexibilidade (chair sit and reach)......................................................... 16

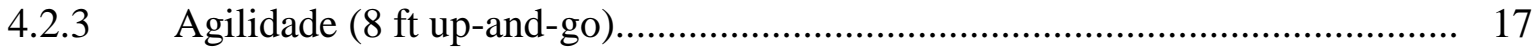

4.2.4 Flexibilidade (back scratch)................................................................ 17 
4.2.5 Força de membros inferiors (chair standing)........................................ 17

4.2.6 Força de membros superiores (arm curl)................................................ 18

4.2.7 Resistência aeróbia (6 min walk)........................................................... 18

4.2.8 Força e potência muscular............................................................................ 18

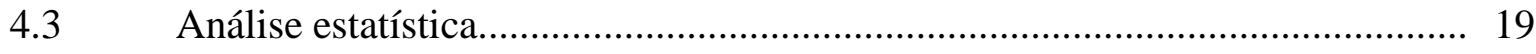

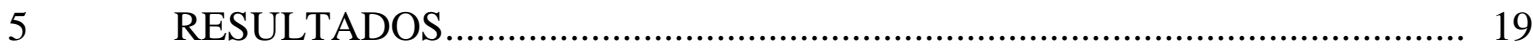

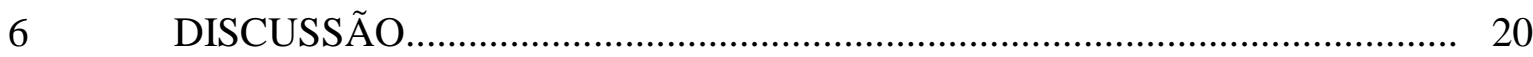

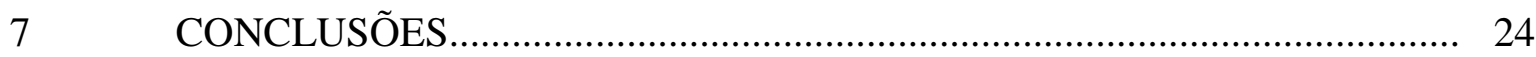

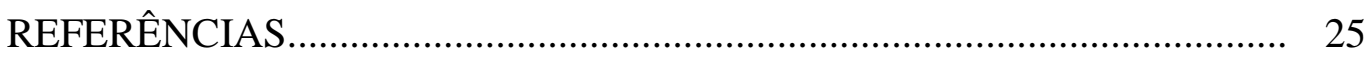




\section{LISTA DE TABELAS}

Página

TABELA 1 - Estudos sobre treinamento com vibração utilizados nesta revisão bibliográfica; onde FD: força dinâmica; FI: força isométrica; DMO: densidade mineral óssea; CVIM: contração voluntária isométrica máxima; CMJ: salto com contra movimento; V: grupo vibração; F: grupo força; VE: grupo exercício+vibração; C: grupo controle; CMC: centro de massa corpórea; MMII: membros inferiores; MMSS: membros superiores

TABELA 2 - Progressão do programa de exercícios do TV durante as 26 sessões.......

TABELA 3 - Resultados de IMC $\left(\mathrm{kg} \bullet \mathrm{m}^{-2}\right)$, sentar e levantar (SL) (repetições), flexão de cotovelo (FC) (repetições), Sentar na cadeira e Levantar (SCA) (repetições), Mãos nas Costas (MC) (distância - $\mathrm{cm}$ ), Agilidade (segundos), Caminhada 6 minutos (C6m) (distância - metros) nos grupos de treinamento vibratório (TV) e grupo controle (GC) pré- e pós treinamento (média \pm desvio padrão)

TABELA 4 - Resultados de Peak Torque $60^{\circ} \cdot \mathrm{s}^{-1}$ (Watt), Power $60^{\circ} \cdot \mathrm{s}^{-1}$ (Watt), Peak Torque $180^{\circ} \cdot \mathrm{s}^{-1}$ (Watt), Power $180^{\circ} \cdot \mathrm{s}^{-1}$ (Watt) nos grupos de treinamento vibratório (TV) e grupo controle (GC) pré- e pós treinamento (média \pm desvio padrão) 
RESUMO

\title{
EFEITO DO TREINAMENTO NA PLATAFORMA VIBRATÓRIA NO DESEMPENHO DE FORÇA E POTÊNCIA MUSCULAR E EM TESTES FUNCIONAIS EM IDOSOS
}

\author{
Autora: RENATA GONÇALVES DA SILVA \\ Orientador: PROF.DR. CARLOS UGRINOWITSCH
}

\begin{abstract}
RESUMO
O objetivo do presente estudo foi investigar o efeito do treinamento de vibração na força e na potência musculares a $60^{\circ} . \mathrm{s}-1$ e a $180^{\circ} . \mathrm{s}-1$ e na funcionalidade de idosos. Participaram do estudo quarenta e sete idosos que já frequientavam um programa de exercícios físicos. Os sujeitos foram divididos em dois grupos: grupo experimental (GE) (n=24, 70.7 \pm 5.8 anos, $62.7 \pm 12.3 \mathrm{~kg}$ e $155.9 \pm 8.0 \mathrm{~cm})$ e grupo controle $(\mathrm{GC})(\mathrm{n}=23,70.0 \pm 5.7$ anos, $65.3 \pm 10.7 \mathrm{~kg}$ e $157.9 \pm 6.6 \mathrm{~cm})$. Adicionalmente ao programa de exercícios físicos, o GE realizou o treinamento de vibração durante 13 semanas, sendo 2 vezes por semana, enquanto que o GC continuou apenas com o programa regular de exercícios físicos. O treinamento de vibração não foi efetivo em melhorar força, potência e o desempenho nos testes funcionais dos idosos. No entanto, encontramos efeito de tempo para os testes de força dos flexores de cotovelo, distância percorrida no teste de caminhada de 6 minutos e redução no tempo para realizar o percurso no teste de agilidade/equilíbrio. Concluindo, o treinamento vibratório não foi efetivo em melhorar a funcionalidade de idosos fisicamente ativos
\end{abstract}


Palavras-chave: vibração, funcionalidade, desempenho, envelhecimento 


\begin{abstract}
EFFECT OF WHOLE BODY VIBRATION TRAINING PROGRAM ON STRENGTH, POWER, AND FUNCTIONAL TESTS IN ELDERLY
\end{abstract}

\author{
Author: RENATA GONÇALVES DA SILVA \\ Adviser: PROF.DR. CARLOS UGRINOWITSCH
}

The aim of this study was to investigate the effect of a whole body vibration training program in the knee extensors isokinetic peak torque and average power, and in functional tests of physically active elderly. Forty seven elderly, whom participated of a training program for the elderly, were recruited. The subjects were divided into two groups; the whole body vibration group (TV) $(\mathrm{n}=24,70.7 \pm 5.8$ years, $62.7 \pm 12.3 \mathrm{~kg}$ e $155.9 \pm 8.0 \mathrm{~cm})$ and the control group (GC) $(\mathrm{n}=23.70 .0 \pm 5.7$ years, $65.3 \pm 10.7 \mathrm{~kg}$ e $157.9 \pm 6.6 \mathrm{~cm})$. The TV performed the whole body vibration exercises and their regular training program for 13 weeks, $2 \times$ per week, while the GC performed the regular training program only. The TV was not effect in increasing both isokinetic peak torque and average power. On the other hand, their regular training program was effective in increasing elbow flexors strength endurance, distance covered in the 6 min walk test, and in speed in the time up and go test. As a conclusion, TV was not effective in improving physically active elderly functionality.

Keywords: vibration, functionality, performance, ageing 


\section{INTRODUÇÃO}

O Brasil vem passando por um processo de envelhecimento nas últimas décadas. Segundo dados do IBGE (2000), na década de 40 do século passado as pessoas com 60 anos ou mais representam 4,1\% da população brasileira, enquanto que em 2000 elas já representavam 8,6\%. Um estudo realizado por Ramos \& Rosa no início dos anos 90, em dez subdistritos do município de São Paulo, com 1602 idosos (60 anos ou mais) revelou que 53\% desses idosos eram totalmente independentes para suas atividades rotineiras e instrumentais de vida diária - preparar refeições, fazer a limpeza da casa, tomar remédios, pentear cabelos, andar no plano, comer, tomar banho, vestir-se, deitar/levantar da cama, ir ao banheiro em tempo, cortar as unhas dos pés, subir um lance de escada, ir a um lugar necessitando de condução e ir andando a um lugar perto de casa. Enquanto 29\% dos idosos necessitavam de ajuda parcial ou total para realizar até três dessas atividades, $10 \%$ precisava de ajuda em mais de três e menos de sete, enquanto $8 \%$ necessitava de ajuda parcial ou total para realizar pelo menos sete dessas atividades.

Essa redução na capacidade do indivíduo em levar uma vida independente acontece, também, em função do declínio da potência e força muscular, que ocorre com o avançar da idade (IZQUIERDO, HAKKINEN, ANTÓN, GARRUES, IBAÑEZ, RUESTA \& GOROSTIAGA, 2001; SIPILA, KOSKINEN, TAAFFE, TAKALA, CHENG, RANTANEM, TOIVANEM \& SUOMINEN, 2004). A literatura específica também indica que essa redução é a principal causa das quedas e fraturas de quadril (GROSS, STEVENSON, CLARETTE, PYKA \& MARCUS, 1998). Mesmo em atividades básicas da vida diária, como caminhar, subir escadas e sentar em uma cadeira, os idosos passam a apresentar limitações que não os permitem realizá-las autonomamente (GROSS et al, 1998, IZQUIERDO et al, 2001; SIPILA et al., 2004).

O treinamento físico pode retardar o declínio, ou aumentar tanto a força quanto a potência muscular e, conseqüentemente, a capacidade funcional do indivíduo ao longo do tempo (ROELANTS, DELECLUSE \& VERSCHUEREN, 2004; VICENT, BRAITH, FELDMAN, MAGYARI, CUTLER, PERSIN, LENNON, GABR \& LOWENTHAL, 2002). Uma das formas de treinamento que vem sendo utilizada para manter a funcionalidade de idosos é através do método chamado Whole Body Vibration (WBV). O sujeito fica em uma 
plataforma que gera uma vibração sinosoidal, em diversas freqüências e amplitudes, que é transmitida para o corpo estimulando os fusos musculares. A ativação dos fusos musculares produz um reflexo vibratório tônico que ativa os motoneurônios alfa. A ativação desses motoneurônios aumenta a produção de força desses, gerando incrementos na produção de força e potência musculares.

Alguns estudos têm indicado que a maior produção de força e potência, após o treinamento vibratório (TV), melhora o desempenho em testes funcionais de idosos (RUSSO, LAURETANI, BANDINELLI, BARTALI, CAVAZZINI, GURALNIK \& FERRUCCI, 2003; VERSCHUEREN, ROELANTS, DELECLUSE, SWINNEN, VANDERSCHUEREN \& BOONEN, 2004). Contudo, não há dados na literatura que indiquem que o TV pode produzir melhoras adicionais na força, na potência e no desempenho em testes funcionais de idosos já fisicamente ativos. Sendo assim, o presente estudo teve por objetivo, verificar o efeito de três meses de treinamento na plataforma vibratória no desempenho de força e potência muscular e em um teste utilizado para avaliar o desempenho em testes funcionais em idosos que já realizam um programa de exercícios físicos.

\section{OBJETIVO}

O objetivo deste estudo foi investigar o efeito de um programa de treinamento na plataforma vibratória no pico de torque e na potência média isocinéticos de extensores de joelho, e em um teste de funcionalidade em idosos fisicamente ativos.

\section{REVISÃO DE LITERATURA}

\subsection{Alterações durante o processo de envelhecimento}

\subsubsection{Aspectos gerais}

O desenvolvimento humano pode ser conceituado como um processo múltiplo e complexo de continuidades e mudanças ao longo do curso da vida, dotado de incrementos, reduções e reorganizações de caráter funcional e estrutural, influenciados pela integração de fatores sociais e comportamentais. O envelhecimento é parte desse processo. 
SHEPHARD (1997) caracterizou o envelhecimento como a diminuição da capacidade de regular a homeostase, resultando numa menor probabilidade de sobrevivência. Nessa fase do desenvolvimento podem ser observadas muitas mudanças nos indivíduos. Entre elas os mecanismos de controle fisiológico não funcionam bem, o tempo de reação está diminuído, a resistência à doença está deficiente, a capacidade de trabalho está reduzida, a recuperação ao esforço é mais lenta e as estruturas do corpo estão menos resistentes. Parte disso deve-se a alterações morfológicas nas fibras musculares e perda de força (sarcopenia) (MATTIELLOSVERZUT, 2003).

SPIRDUSO (1995) usa a palavra aging (envelhecimento) para se referir a um processo ou conjunto de processos que ocorrem nos organismos vivos e que, com o passar do tempo, induzem a perda da adaptabilidade, diminuição das capacidades funcionais, e eventualmente à morte.

Mas, o envelhecimento não consiste apenas em um processo de perdas; o organismo que a essa altura, espera-se, carrega uma grande experiência motora e biológica, consegue promover várias adaptações que objetivam a sobrevivência nas melhores condições que lhe é permitido (MOTA, 2002).

Atualmente ainda não é claro o limite entre os conceitos de envelhecimento e deficiência, por isso, muitas vezes nos deparamos com a visão negativa desta fase do desenvolvimento (SANTOS, 1990). É fato para toda a comunidade científica que as mudanças relacionadas ao envelhecimento são um problema coletivo, ou seja, de todo indivíduo que atinge uma determinada fase de desenvolvimento. Sendo assim, envelhecer não está relacionado diretamente a adoecer, uma vez que mudanças, declínios ou limitações de alguns subsistemas são esperados dentro desse processo. Tais limitações são decorrentes do envelhecimento "normal" do ser humano, inerentes ao processo de desenvolvimento (BROOKS \&, FAHEY, 1983; SANTOS, 1990).

De fato muitas das causas associadas à inaptidão, ou mesmo à diminuição funcional dos indivíduos, devem ser imputadas não tanto à degenerescência associada ao processo ontológico do envelhecimento, mas à ausência de estimulação suficiente, melhor dizendo, ao desuso (FRONTERA, MEREDITH, O’REILLY, KNUTTGEN \&, EVANS, 1988; SPIRDUSO, 1995). Ou seja, algumas das alterações morfológicas e funcionais parecem estar associadas à maior taxa de sedentarismo das pessoas idosas, e não tão somente ao envelhecimento celular. Logo, a idéia que se estabelece no contexto que nos rodeia, é a de 
saber o papel da atividade física na melhoria da QV do sujeito, em particular da pessoa idosa, levando em consideração suas características e necessidades específicas (MOTA, 2002).

A existência de pessoas idosas em excelente forma física e mental ainda é admirável e estranho aos olhos da sociedade. Apesar de se saber que é possível envelhecer com saúde e independência. A taxa do processo degenerativo pode ser alterada pela atividade física, nomeadamente por meio de modificações seletivas na composição corporal, nas aptidões metabólicas e físicas. De fato, em alguns processos, essas modificações parecem fazer o “tempo parar". Os objetivos de tantas pesquisas nessa área (ACSM, 1998; AOYAGI \& SHEPHARD, 1992; FIATARONE, MARKS, RYAN, MEREDITH, LIPSITZ \& EVANS, 1990; FIATARONE, O`NEIL, RYAN, CLEMENTS, SOLARES, NELSON, ROBERTS, KEHAYIAS, LIPSITZ \& EVANS, 1994; FRONTERA \& BIGARD, 2002; OKUMA, 1998; SERRÃO \& AMADIO, 1994; SPIRDUSO, 1995; WINTER, PATIA, FRANK \& WALT, 1990.) são os de entender como algumas pessoas conseguem chegar a idades avançadas esbanjando saúde; desenvolver novos ou melhores métodos de intervenção que permitam ao ser humano viver mais e com melhor qualidade de vida.

\subsubsection{Características musculares}

A força muscular máxima é atingida entre os 20 e 30 anos de idade e por volta dos 40 começa uma acelerada perda do tecido contrátil, provocando decréscimos na produção de força dinâmica e estática e na velocidade dos movimentos (AOYAGI \& SHEPHARD, 1992; SPIRDUSO, 1995). A quantidade de força que um indivíduo pode produzir depende substancialmente do estado do aparelho mioarticular do indivíduo, do seu sistema nervoso, da quantidade de trabalho muscular exigida por uma determinada tarefa e do seu nível de treinamento. Porém é comum observarmos grandes variações entre indivíduos e isso pode ocorrer quando eles têm uma grande diferença de massa muscular (MM): homens, por exemplo, são mais fortes que mulheres por terem maior MM (em média).

A MM, que pode ser mensurada através de tomografia computadorizada (TC), declina substancialmente com a idade e, conseqüentemente provoca quedas na produção de força muscular (BROOKS \& FAHEY, 1983; MATTIELLO-SVERZUT, 2003; WILMORE \& COSTILL, 2001). Estudos que utilizaram a técnica de TC evidenciaram que após os 30 anos de idade existe uma diminuição na área de secção transversa do quadríceps, na densidade 
muscular e um aumento na gordura intramuscular (MAZZEO, CAVANAGH, EVANS, FIATARONE, HAGBERG, McAULEY \& RTZELL, 1998; AOYAGI \& SHEPHARD, 1992).

Segundo BROOKS \& FAHEY (1983), um importante fator que também pode alterar a produção de força é a perda da capacidade bioquímica do músculo. Esse processo ocorre devido à caracterizada diminuição das enzimas succinato, piruvato e malato dehidrogenases e da citocromo oxidase, importantes na produção de ATP, além da diminuição da massa mitocondrial

Outra característica marcante do processo de envelhecimento é a relação entre os tipos de fibras musculares do indivíduo idoso. Em sujeitos com mais de 60 anos são encontradas poucas fibras do Tipo II (rápidas e brancas) quando comparados a indivíduos mais jovens, essas fibras passam de 60\% em adultos jovens para 30\% em homens sedentários com mais de 80 anos (MATTIELLO-SVERZUT, 2003). O processo pelo qual se dá essa diferença ainda é bastante controverso. Existem indícios de que as fibras do tipo II são mais sensíveis ao processo de envelhecimento (AOYAGI \& SHEPHARD, 1992; LARSSON, 1983; WILMORE \& COSTILL, 2001). Mas também há a hipótese de que algumas fibras do tipo II perdem sua inervação original e são re-inervadas por motoneurônios do tipo I (MATTIELLO-SVERZUT, 2003; SPIRDUSO, 1995). No entanto isso também pode estar relacionado ao tipo de músculo envolvido e sua atividade, como o caso do músculo sóleo, que apresenta maior atividade oxidativa e, portanto suas fibras tipo II são raramente estimuladas, podendo transformar-se em tipo I ou até mesmo morrer (MATTIELLO-SVERZUT, 2003).

\subsubsection{Sarcopenia}

$\mathrm{Na}$ senescência são observadas alterações musculares de caráter estrutural, como o tamanho das fibras musculares, o número e proporção dos diferentes tipos de fibras - tipo I e tipo II e seus subtipos - e ultraestrutural (BROOKS \& FAHEY, 1983; FIATARONE, et al., 1990; FIATARONE, et al., 1994; LARSSON, 1983). As unidades motoras também apresentam modificações de caráter estrutural e funcional, que parecem ser induzidas pelo sistema nervoso central (MATTIELLO-SVERZUT, 2003; SPIRDUSO, 1995). Essas alterações geram comprometimento da massa muscular e modulam o grau de geração de força, o que define o processo de sarcopenia (MATTIELLO-SVERZUT, 2003). Essa perda de força pode ser atribuída também, à redução no número de unidades motoras (AKATAKI, MITA, 
WATAKABE \& ITO, 2002), principalmente das UM rápidas. Dessa forma, as características mecânicas dos músculos esqueléticos dos idosos para ser determinada principalmente pela funcionalidade das UMs lentas, em função da deterioração das unidades motoras rápidas.

Além disso, em idosos, existem fortes indícios de que uma substancial quantidade de tecido muscular pode ser substituída pelos tecidos conectivo e adiposo (BROOKS \& FAHEY, 1983; MATTIELLO-SVERZUT, 2003).

Os estudos relacionados à queda da MM e o aumento da idade, principalmente após os 70 anos, sugerem que essa queda seja decorrente, em maior parte, da diminuição do tamanho e do número de fibras (MAZZEO et al., 1998; LARSSON, 1983) e também do desuso (FIATARONE et al., 1990).

Em humanos, há indícios de que as alterações induzidas pela senescência podem ser desencadeadas também por perda de neurônios motores a (MATTIELLO-SVERZUT, 2003; ROUBENOFF, 2000; SPIRDUSO, 1995). Na sétima década da vida, a perda de neurônios motores e de unidades motoras parece desenvolver-se para músculos proximais e distais, e chega a comprometer cerca da metade das unidades motoras apresentadas nos adultos jovens (SPIRDUSO, 1995).

A reduzida capilarização muscular em indivíduos idosos sedentários, significativamente menor do que de indivíduos jovens e a menor síntese protéica nos idosos também são alterações observadas que podem influenciar no processo de sarcopenia (FIATARONE, et al.1994; MATTIELLO-SVERZUT, 2003).

Embora saibamos que há controvérsias a respeito dos motivos que levam ao declínio da MM com passar dos anos, existem fortes evidências de que esse declínio pode ser menos acentuado em indivíduos que mantêm um estilo de vida saudável, como uma boa dieta e a prática de exercícios de força muscular.

\subsection{Execução das AVD’s e a perda funcional em idosos}

A independência funcional de um indivíduo está diretamente relacionada à capacidade deste em realizar as tarefas diárias sem a ajuda de terceiros. Segundo HAWKINS, EKLUND \& JINGYI (1999) elas estão divididas em dois grupos:

- AVD: são as atividades da vida diária; incluem atividades que envolvem cuidados pessoais como tomar banho, se vestir, se alimentar, caminhar, subir escadas; 
- AIVD: são as atividades instrumentais da vida diária; incluem atividades como ir às compras, cozinhar, cuidar da casa;

O envelhecimento muitas vezes vem acompanhado por um processo de deficiência (MAZZEO et al., 1998; REEVES, MAGNANARIS \& NARICI, 2004). Este pode estar relacionado a um quadro de doenças crônicas, tais como doenças coronárias e pulmonares, mas também pode estar relacionado à diminuição da aptidão física do indivíduo. É esta diminuição da aptidão que interfere diretamente na capacidade de realizar as AVD.

Estudos relatam que, dentre idosos, é grande o número de indivíduos que necessitam da ajuda de terceiros na realização dessas atividades (ACSM, 1998). Portanto, uma boa condição física para o idoso tem sido considerada um componente fundamental para a manutenção de uma vida independente no âmbito familiar e social.

Ao mesmo tempo, muitos estudos indicam que o exercício físico bem planejado e gerenciado é capaz de aumentar a aptidão física de idosos e, portanto, capaz de diminuir e até mesmo reverter esse quadro de capacidade funcional reduzida (FIATARONE et al., 1990; MISZKO, CRESS, SLADE, COVEY, GRAWAL \& DOER, 2003). No entanto, é importante saber qual o tipo de treinamento é mais eficiente para a melhoria da funcionalidade entre idosos, uma vez que existem muitas estratégias exeqüíveis para este grupo populacional. É possível encontrar na literatura especializada, diferentes tipos de protocolos para avaliar a interferência dessas estratégias na melhoria da funcionalidade. Neste estudo, foi utilizada a bateria de testes de Fullerton (RIKLI \& JONES, 1999), que tem o intuito de verificar o nível de aptidão dos idosos para executar atividades da vida diária (AVDs).

\subsection{Treinamento de vibração}

A vibração é caracterizada por uma sequência de movimentos oscilatórios que se repetem em torno de uma determinada posição. Essa movimentação pode ser aleatória ou periódica, neste último caso, formando ondas.

O treinamento de vibração (TV) é um método de treinamento neuromuscular, no qual o sujeito permanece sobre uma plataforma capaz de gerar ondas constantes em forma de sino (DELECLUSE et al., 2003).

Devido à característica simétrica das ondas, é possível medir a intensidade da vibração gerada por esses aparelhos, determinando a amplitude das ondas e a frequiência com que os deslocamentos acontecem. A diferença entre o menor e o maior valor do deslocamento durante 
a oscilação ou, como em alguns estudos, a metade da diferença entre eles, é a amplitude, normalmente fornecida em milímetros $(\mathrm{mm})$. Já a freqüência da vibração corresponde à taxa de repetições dos deslocamentos, em ciclos por segundo, e por isso sua unidade é o Hertz $(\mathrm{Hz})$ (CARDINALE \& BOSCO, 2003). Além da amplitude e da freqüência, a aceleração é outra variável que quantifica a intensidade da vibração. É determinada através da amplitude e da freqüência de vibração, pela fórmula $a=(2 f)^{2} * d$; onde, $f$ corresponde à freqüência das oscilações e $d$, seu deslocamento. É expressa em metros por segundo ao quadrado $\left(\mathrm{m} / \mathrm{s}^{2}\right)$ ou em relação ao número de vezes que supera a aceleração gravitacional $(\mathrm{g})$. Porém, a maneira mais precisa para sua determinação é por meio de um acelerômetro.

É através da manipulação da amplitude, da freqüência e do tempo de exposição à vibração que a intensidade do treinamento é estipulada. Atualmente, no mercado estão disponíveis plataformas de vibração capazes de gerar amplitudes entre 2-10mm, frequiências entre $12-50 \mathrm{~Hz}$ e que controlam o tempo de exposição, que varia entre 30 a 60s.

No TV os aparelhos utilizados são classificados de acordo com a maneira pela qual a vibração é imposta ao corpo humano: os de vibração direta e os de vibração indireta (LUO et al., 2005). As plataformas e os halteres vibratórios são aparelhos produtores de vibração de maneira indireta, sendo as plataformas mais comumente utilizadas. Em ambos os aparelhos, os pés, no caso das plataformas ou as mãos, no caso dos halteres, estão em contato com o aparelho vibratório. Se o sujeito permanecer em pé sobre a plataforma, a vibração produzida propagar-se-á por muitos grupos musculares, ossos e órgãos do corpo, permitindo assim, uma maior influência da vibração. No caso do método direto, a vibração é especificamente direcionada ao músculo com o qual o aparelho está em contato, e os tecidos vizinhos praticamente não são atingidos pela vibração.

Além dessas variáveis, a proximidade da fonte emissora de vibração promove maior efeito nessa estrutura e, quanto maior o estado de ativação muscular, maior será o efeito da vibração (ROELANTS et al., 2006; VERSCHUEREN et al., 2003). Essa evidência sugere que para otimizar o TV este deveria ser realizado conjuntamente com uma outra forma de exercício ou atividade muscular intensa. Porém, após a revisão de literatura, foi possível observar que na maioria dos estudos o sujeito realizava exercícios sobre a plataforma suportando apenas seu peso corporal (ROELANTS et al., 2004; RUSSO et al., 2003; VERSCHUEREN et al, 2004) e poucos estudos combinaram o TV com o treinamento de força convencional (BAUTMANS et al., 2005; RONESTAD et al., 2004). 
É possível também, utilizar a combinação das variáveis amplitude, freqüência, tempo de exposição e adição ou não de sobrecarga, assim como a manipulação do número de séries realizadas em uma sessão, a freqüência de treinamento semanal e a duração total do programa, a fim de se obter uma periodização para o treinamento.

\subsubsection{Mecanismos fisiológicos que explicam os efeitos da vibração}

Em um artigo de revisão, LUO et al. (2005) afirmaram que, freqüentemente, são apontados como mecanismos responsáveis pelos efeitos produzidos pelo método de vibração, a ativação do reflexo tônico de vibração, a modificação na percepção da vibração, o aumento da excitabilidade dos neurônios motores, o aumento da temperatura e do fluxo sanguíneo musculares, o aumento da secreção hormonal e a hipertrofia muscular. Segundos os autores, poucos estudos tentaram elucidar os mecanismos pelos quais a vibração produz melhoras no desempenho, e que, além disso, não há consenso entre os estudos existentes.

Por outro lado, as revisões de CARDINALE \& BOSCO (2003) e JORDAN et al. (2005), se aprofundaram mais sobre esta questão. Um importante destaque que os dois grupos de autores fazem é que, ao tentar entender os mecanismos pelos quais a vibração produz melhoras no desempenho, deve-se distinguir entre os efeitos que são verificados durante a aplicação da vibração (efeitos agudos), imediatamente após sua aplicação (efeitos agudos residuais) e após a aplicação de uma série de sessões de vibração ao longo do tempo (efeitos crônicos). Os estudos realizados com idosos somente analisaram os efeitos do TV cronicamente.

Não existe muito consenso a respeito dos mecanismos fisiológicos que suportam os efeitos crônicos da vibração. Porém, parece que a indução do reflexo tônico de vibração (RTV) e a conseqüente maior ativação muscular produzidas durante a vibração influenciam de alguma maneira, a manifestação dos efeitos crônicos, já que, em alguns estudos o treinamento com vibração mostrou aumentos mais importantes de força em comparação com o treinamento convencional. O RTV consiste da ativação de um mecanismo reflexo, desencadeado pelas rápidas e curtas modificações no comprimento do complexo músculo-tendíneo, produzidas pela exposição à vibração. A ativação desse reflexo é semelhante a do reflexo de estiramento. Ou seja, as alterações do comprimento muscular são transmitidas através dos neurônios sensoriais Ia até a medula espinhal onde, através de um circuito mono ou poli-sináptico, ativam os neurônios motores alfa $(\alpha)$ homônimos e seus sinergistas, causando uma contração tônica dos respectivos músculos (CARDINALE \& BOSCO, 2003; JORDAN, 2005). 
De maneira geral, os efeitos crônicos do treinamento com vibração têm sido atribuídos aos mesmos mecanismos que explicam a melhora de desempenho com o treinamento convencional, isto é, adaptações neurais como, aumento do recrutamento, da sincronização e da freqüência de disparos das unidades motoras, e hipertrofia muscular.

Segundo CARDINALE \& BOSCO (2003) o aumento da sobrecarga gravitacional, seria responsável por tais adaptações. Primeiro, por proporcionar uma maior ativação muscular a fim de contra atuar à ação da força g aumentada. Segundo por ativar a produção dos hormônios anabolizantes testosterona e GH (hormônio do crescimento), que poderia explicar a hipertrofia observada após o treinamento com vibração.

\subsubsection{Tempo de manifestação dos efeitos da vibração}

Os estudos mostram que os efeitos do TV podem ocorrer tanto agudamente, ou seja, minutos após a aplicação da vibração, como cronicamente (COCHRANE et al., 2005; ROELANTS et al., 2004; TORNIVEN et al., 2002; VERSCHUEREN et al., 2004).

No entanto, todos os estudos utilizados nesta revisão (ver tabela 1) e relacionados a idosos apresentaram protocolos que variaram entre seis e 24 semanas de treinamento, com duas a três sessões de treino por semana (BAUTMANS et al., 2005; BRUYERE et al., 2005; ROELANTS et al., 2004; RUSSO et al., 2006; VERSCHUEREN et al., 2004; KAWANABE et al., 2007). Neles, as principais variáveis analisadas foram forças dinâmica e isométrica e potência de membros inferiores; alguns estudos analisaram também a marcha, o equilíbrio, a agilidade e a densidade mineral óssea.

\subsubsection{Efeitos do treinamento de vibração em idosos}

Visando minimizar os efeitos do processo de sarcopenia, que começa por volta da quarta década de vida e é responsável pelo decréscimo da capacidade de produção de força e da velocidade de realização dos movimentos (SPIRDUSO, 1995) interferindo na qualidade de vida das pessoas, o treinamento com vibração também tem sido testado em idosos. Um outro motivo para sua utilização é a ausência dos desconfortos gerados pelas outras técnicas de treino, como é o caso da dor pós treino produzida com o treinamento de força, também aplicado em idosos (BAUTMANS et al., 2005). 
$\mathrm{Na}$ literatura, foram selecionados sete artigos sobre o TV em idosos (BAUTMANS et al., 2005; BOGAERTS et al., 2007; BRUYERE et al., 2005; KAWANABE et al., 2007; ROELANTS et al., 2004; RUSSO et al., 2003; VERSCHUEREN et al., 2004;).

Esses artigos mostraram que esse tipo de treinamento pode ser perfeitamente aplicado em idosos. Além disso, eles sugerem que o TV pode ser igualmente eficiente ao treinamento de força em relação à melhora dessa capacidade entre a população idosa (entre 12,1\% e 16,5\% de aumento na força dinâmica e $15 \%$ na força isométrica). Ao analisarem os efeitos do TV na potência (BAUTMANS et al., 2005; ROELANTS et al., 2004) os estudos sugerem que esse novo método de intervenção pode obter resultados positivos na melhora dessa capacidade (16\% no salto vertical com contra movimento), o que pode otimizar a qualidade de vida dessas pessoas. Adicionalmente, também foi possível observar em três desses artigos (BAUTMANS et al., 2005; BRUYERE et al., 2005; KAWANABE et al., 2007) resultados positivos na melhora do equilíbrio e da agilidade (melhora no equilíbrio no teste de equilíbrio com apoio unipodal $65 \%$ lado direito e $88,4 \%$ lado esquerdo e melhora de 3,5 pontos no teste de equilíbrio utilizado por BRUYERE et al. (2005). Um único estudo (VERSCHUEREN et al., 2004) relata efeitos positivos na manutenção da densidade mineral óssea em mulheres na terceira idade $(0,93 \%)$.

No entanto, pelo reduzido número de estudos encontrados na literatura, são necessárias mais pesquisas utilizando esse método de treinamento com o intuito de confirmar os resultados existentes. 
Tabela 1: Estudos sobre treinamento com vibração utilizados nesta revisão bibliográfica; onde FD: força dinâmica; FI: força isométrica; DMO: densidade mineral óssea; CVIM: contracão voluntária isométrica máxima; CMJ: salto com contramovimento; V: grupo vibração; F: grupo força; VE: grupo exercício+vibração; Eq: Equilíbrio; CF: Cond Físico; CA: Caminhada; C: grupo controle; CMC: centro de massa corpórea; MMIl: membros inferiores: MMSS: membros superiores.

\begin{tabular}{|c|c|c|c|c|c|c|c|c|c|c|}
\hline Autor & $\begin{array}{l}\text { Característica } \\
\text { dos sujeitos }\end{array}$ & Design & Tratamento & $\begin{array}{l}\text { Característica } \\
\text { da vibração }\end{array}$ & $\begin{array}{l}\text { Caracteristica } \\
\text { do exercicio } \\
\text { grupo Vibração }\end{array}$ & $\begin{array}{l}\text { Caracteristica } \\
\text { do exercicio } \\
\text { grupo Força }\end{array}$ & \begin{tabular}{|} 
Duração \\
do \\
estudo
\end{tabular} & $\begin{array}{c}\text { Variáveis } \\
\text { dependentes }\end{array}$ & Resultados & Observações \\
\hline $\begin{array}{l}\text { Russo, } \\
2003\end{array}$ & $\begin{array}{c}29 \text { M pos- } \\
\text { menopausa; } \\
54-68 \text { anos } \\
\text { (Não descreve } \\
\text { nível de } \\
\text { condicionamento } \\
\text { físico inicial) }\end{array}$ & VE; C & $\begin{array}{c}\text { TV } \\
\text { 2x/semana+ } \\
\text { suplementação }\end{array}$ & $\begin{array}{l}12-28 \mathrm{~Hz} \\
0,1-10 \mathrm{~g}\end{array}$ & $\begin{array}{l}\text { Mantinham } \\
\text { joelhos } \\
\text { semiflexionados } \\
\text { durante } \\
\text { vibração }\end{array}$ & suplementação & $\begin{array}{c}24 \\
\text { semanas } \\
(48 \\
\text { sessões })\end{array}$ & $\begin{array}{l}\text { potência MMII; vel } \\
\text { deslocamento } \\
\text { CMC; DMO } \\
\text { (cortical) }\end{array}$ & $\begin{array}{c}\vee \uparrow 5 \% \text { potência, } C \downarrow ; \\
\vee \uparrow 4,8 \% \text { vel desl } \\
\text { CMC; DMO (cortical) } \\
\text { não sofreu alteração } \\
\text { em nenhum dos } \\
\text { grupos }\end{array}$ & $\begin{array}{c}\text { Apenas 200min } \\
\text { de exposição à } \\
\text { vibração; houve } \\
\text { diferença } \\
\text { significativa entre } \\
\text { grupos em } \\
\text { relação à } \\
\text { potência. }\end{array}$ \\
\hline $\begin{array}{l}\text { Verschuren, } \\
2004\end{array}$ & $\begin{array}{c}70 \text { M pos- } \\
\text { menopausa; } \\
\text { 58-74anos } \\
\text { Não descreve o } \\
\text { nível de } \\
\text { condicionamento } \\
\text { físico inicial - não } \\
\text { institucionalizadas) } \\
\end{array}$ & VE; F; C & $\begin{array}{c}\text { TV } \\
3 \mathrm{x} / \text { semana }\end{array}$ & $\begin{array}{l}35-40 \mathrm{~Hz} \\
1.7-2.5 \mathrm{~mm} \\
(2,28-5.1 \mathrm{~g})\end{array}$ & $\begin{array}{l}\text { agach. variados } \\
\text { estáticos e } \\
\text { dinâmicos }\end{array}$ & $\begin{array}{l}\text { 20-8RM; leg } \\
\text { press, cadeira } \\
\text { extensora }\end{array}$ & $\begin{array}{c}24 \\
\text { semanas } \\
(72 \\
\text { sessões })\end{array}$ & $\begin{array}{l}\text { força; DMO (qudril } \\
\text { e lombar); massa } \\
\text { gorda; marcadores } \\
\text { biológicos de } \\
\text { fixação de } \mathrm{Ca}+\end{array}$ & \begin{tabular}{|c|} 
V: $\uparrow$ FI $15 \% ; \uparrow$ FD \\
$16,5 \% ; \mathrm{DMO} \uparrow 0,93 \% ;$ \\
$\downarrow 2,3 \% \%$ gord \\
F: $\uparrow$ FI 16\%; $\uparrow$ força \\
din. $10,6 \% ;$ DMO \\
$\downarrow 0,51 \% ; \%$ \\
gord. $\downarrow 3,1 \%$ \\
\end{tabular} & $\begin{array}{l}\text { Houve diferença } \\
\text { no aumentoda } \\
\text { DMO e esta, } \\
\text { aumentou no } \\
\text { quadril, mas não } \\
\text { na coluna, } \\
\text { indicando efeito } \\
\text { local }\end{array}$ \\
\hline $\begin{array}{l}\text { Roelants, } \\
2004\end{array}$ & $\begin{array}{c}69 \mathrm{M} \text { pos- } \\
\text { menopausa; } 58-74 \\
\text { anos } \\
\text { Sedentárias }\end{array}$ & VE; F; C & $3 x /$ semana & $\begin{array}{l}35-40 \mathrm{~Hz} \\
2,5-5 \mathrm{~mm} \\
(2.28-5.1 \mathrm{~g})\end{array}$ & $\begin{array}{c}\text { Exercícios } \\
\text { estáticos para } \\
\text { mebros } \\
\text { inferiores }\end{array}$ & $\begin{array}{l}\text { 20-8 RM leg } \\
\text { press; cadeira } \\
\text { extensora }\end{array}$ & $\begin{array}{c}12 \text { e } 24 \\
\text { semanas } \\
(72 \\
\text { sessões })\end{array}$ & \begin{tabular}{|c|} 
força isométrica e \\
dinâmica; vel mov \\
na ext joelho (1, \\
20,40 e $60 \%$ \\
CVIM); CMJ
\end{tabular} & \begin{tabular}{|c|}
12 sem pós: VE: $\uparrow$ \\
FI= $15 \% ; \uparrow F D$ \\
$12,1 \% ; \uparrow C M J 16 \%$ \\
F: $\uparrow$ FI= 16,8\%; $\uparrow F D$ \\
$12,5 \% ; \uparrow$ CMJ \\
$12,1 \% ;$ \\
24 sem pós: VE $\uparrow F D$ \\
$3,7 \%, \uparrow 7,4 \%$ vel mov \\
em relação ao pré a \\
1\%CVIM e $\uparrow 6,3 \%$ a \\
$20 \% 1 C V I M$. \\
\end{tabular} & $\begin{array}{c}\text { melhoras após } \\
12 \text { e } 24 \text { semanas } \\
\text { não foram } \\
\text { diferentes entre } \\
\text { VE e F. }\end{array}$ \\
\hline $\begin{array}{l}\text { Bruyere, } \\
2005\end{array}$ & $\begin{array}{c}11 \mathrm{H} \text { e } 31 \mathrm{M} ; 81,9 \\
+/-6,9 \text { anos } \\
\text { Institucionalizados }\end{array}$ & VE; E & $3 x /$ semana & $\begin{array}{c}26 \mathrm{~Hz} ; \\
(3-7 \mathrm{~mm})\end{array}$ & $\begin{array}{l}\text { Permanecem na } \\
\text { plataforma (não } \\
\text { descreve a } \\
\text { posição)! }\end{array}$ & $\begin{array}{l}\text { Exercícios } \mathrm{p} / \\
\text { marcha, } \\
\text { equilíbrio e } \\
\text { flexibilidade } \\
\text { para MMII }\end{array}$ & $\begin{array}{c}6 \\
\text { semanas } \\
(18 \\
\text { sessões })\end{array}$ & $\begin{array}{c}\text { equilíbrio, } \\
\text { qualidade da } \\
\text { marcha, teste de ir } \\
\text { e voltar }\end{array}$ & \begin{tabular}{|c|}
$\uparrow 2,4$ qualidade da \\
marcha, $\uparrow 3,5$ \\
equilíbrio; $\downarrow 11$ seg o \\
tempo do teste de ir e \\
voltar.
\end{tabular} & $\begin{array}{c}\text { Houve diferença } \\
\text { entre os grupos. } \\
\text { Dados fornecidos } \\
\text { em scores. }\end{array}$ \\
\hline
\end{tabular}




\begin{tabular}{|c|c|c|c|c|c|c|c|c|c|c|}
\hline Autor & $\begin{array}{l}\text { Característica } \\
\text { dos sujeitos }\end{array}$ & Design & Tratamento & $\begin{array}{c}\text { Característica } \\
\text { da vibração }\end{array}$ & $\begin{array}{c}\text { Caracteristica } \\
\text { do exercicio } \\
\text { grupo Vibração }\end{array}$ & $\begin{array}{l}\text { Caracteristica } \\
\text { do exercicio } \\
\text { grupo Força }\end{array}$ & $\begin{array}{c}\text { Duração } \\
\text { do } \\
\text { estudo }\end{array}$ & $\begin{array}{c}\text { Variáveis } \\
\text { dependentes }\end{array}$ & Resultados & Observações \\
\hline $\begin{array}{l}\text { Bautmans, } \\
2005\end{array}$ & $\begin{array}{c}15 \mathrm{M} \mathrm{e} 9 \mathrm{H} \\
77,5+/-11 \text { years; } \\
\text { institucionalizados }\end{array}$ & $\mathrm{V}+\mathrm{F} ; \mathrm{F}$ & $3 x /$ semana & $\begin{array}{c}30-50 \mathrm{~Hz} \\
(2-5 \mathrm{~mm})\end{array}$ & $\begin{array}{l}\text { Exercícios } \\
\text { estáticos para } \\
\text { mebros } \\
\text { inferiores }\end{array}$ & $\begin{array}{c}\text { Exercícios } \\
\text { estáricos para } \\
\text { mebros } \\
\text { inferiores }\end{array}$ & $\begin{array}{c}6 \\
\text { semanas } \\
(18 \\
\text { sessões })\end{array}$ & $\begin{array}{l}\text { MMII: FD } 40 \text { e } \\
60 c m . s-1 ; \\
\text { potência; tempo } \\
\text { de levantar- ir-e- } \\
\text { voltar; equilíbrio; } \\
\text { marcha; } \\
\text { flexibilidade; } \\
\text { MMSS: prensão } \\
\text { manual, } \\
\text { flexibilidade }\end{array}$ & $\begin{array}{l}\text { لtempo de levantar-ir- } \\
\text { e-voltar }(-3,3 \mathrm{~s}) ; \uparrow \\
\text { equlibrio. }\end{array}$ & $\begin{array}{l}\text { Houve diferença } \\
\text { entre grupos } \\
\text { apenas para o } \\
\text { teste de marcha } \\
\text { e equilíbrio } \\
\text { (Tinetti-test) }\end{array}$ \\
\hline $\begin{array}{l}\text { Kawanabe, } \\
2005\end{array}$ & $\begin{array}{l}4 \text { H e } 67 \text { M pos- } \\
\text { menopausa; } \\
59-86 \text { anos } \\
\text { Sedentários }\end{array}$ & $\begin{array}{l}\text { V+Eq. Alo } \\
\text { CA; } \\
\text { Eq. Alo, } \\
\text { CA }\end{array}$ & 1x/semana & $12-20 \mathrm{~Hz}$ & $\begin{array}{l}\text { Movimento de } \\
\text { Step na } \\
\text { plataforma }\end{array}$ & $\begin{array}{l}\text { Exercícios de } \\
\text { equilíbrio e } \\
\text { alongamento de } \\
\text { membros } \\
\text { inferiores }\end{array}$ & $\begin{array}{c}2 \text { meses } \\
(8 \\
\text { sessões })\end{array}$ & $\begin{array}{l}\text { Potência (tempo } \\
\text { de } 10 \mathrm{~m} \\
\text { caminhada) } \\
\text { Equilíbrio } \\
\text { (comprimento do } \\
\text { passo, Tempo } \\
\text { máximo em uma } \\
\text { única perna) }\end{array}$ & $\begin{array}{c}V+\mathrm{Eq} \\
\downarrow \text { tempo } 10 \mathrm{~min} \\
\text { caminhada }(14,9 \%) \\
\uparrow \text { tempo máximo em } \\
\text { uma única perna (dir } \\
65 \% \text { e esq } 88,4 \%) \\
\uparrow \text { o comprimento do } \\
\text { passo }(6,5 \%)\end{array}$ & $\begin{array}{c}\text { Houve melhora } \\
\text { apenas no grupo } \\
\vee+\text { +eq - dif. } \\
\text { Significante entre } \\
\text { os grupos }\end{array}$ \\
\hline $\begin{array}{l}\text { Bogaerts, } \\
2007\end{array}$ & $\begin{array}{l}46 \mathrm{M} \mathrm{e} 48 \mathrm{H} \\
60-80 \text { anos } \\
\text { Sedentários }\end{array}$ & $\begin{array}{l}\mathrm{V}+\mathrm{CF} \\
\mathrm{CF}, \mathrm{C}\end{array}$ & 3x/semana & $30-40 \mathrm{~Hz}$ & $\begin{array}{c}\text { Exercícios } \\
\text { estáticos e } \\
\text { dinâmicos } \\
\text { (agachamentos) } \\
\text { para membros } \\
\text { inferiores }\end{array}$ & $\begin{array}{c}\text { Exercícios } \\
\text { aeróbios, força, } \\
\text { equilíbrio e } \\
\text { flexibilidade }\end{array}$ & 1 ano & $\begin{array}{c}\text { Teste de } \\
\text { organizaçãao } \\
\text { sensorial (TOS); } \\
\text { Teste de controle } \\
\text { motor(TCM); }\end{array}$ & $\begin{array}{l}\text { TOS } \uparrow \text { apenas com } \\
\text { a plataforma } \\
\text { movimentando ( } \mathrm{V} \text { e } \\
\text { CF) }\end{array}$ & $\begin{array}{l}\text { Dados fornecidos } \\
\text { em scores }\end{array}$ \\
\hline
\end{tabular}




\section{METODOLOGIA}

\subsection{Amostra}

A amostra foi composta por 47 sujeitos fisicamente ativos. Os indivíduos faziam parte de um programa de exercício físico (CEFI - Curso de Educação Física para Idosos) na Escola de Educação Física e Esporte da Universidade de São Paulo, que realizavam no mínimo duas sessões de treinamento por semana. Todos os participantes tinham autorização médica para participar dos testes e do treinamento. Foi solicitado aos indivíduos que mantivessem suas atividades diárias durante toda a duração do estudo. Todos foram informados dos possíveis riscos, desconfortos e benefícios do estudo e consentimento escrito para a participação foi obtido.

\subsubsection{Formação dos grupos}

Após o processo de seleção os sujeitos foram divididos em dois grupos (experimental e controle). O grupo experimental foi composto por 5 homens e 19 mulheres

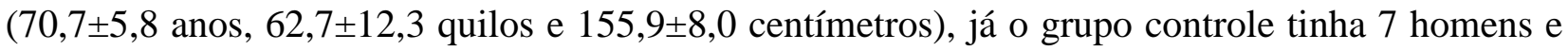

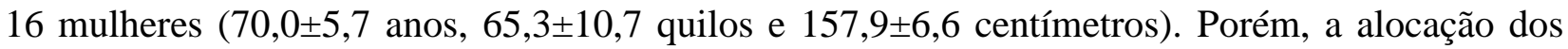
sujeitos aos grupos não foi feita de forma aleatória para permitir que os grupos fossem equalizados quanto ao nível de aptidão física pré-treinamento. Primeiro, os indivíduos realizaram os pré-testes e foram divididos em quartis. Segundo, os indivíduos dos quartis foram alocados aleatoriamente nos grupos experimental (GE) e controle (GC). Dessa forma, os grupos tinham o mesmo número de indivíduos de cada quartil e, por isso, condição inicial similar.

\subsubsection{Grupo controle}

Os sujeitos participaram somente do programa do CEFI (Curso de Educação Física para Idosos), durante 13 semanas, duas vezes por semana na EEFE-USP. Em linhas gerais, o treinamento tinha duração de 1 hora, com exercícios de propriocepção/equilíbrio (10 min.), aeróbio (20 min.), força (20 min.) e alongamento (10 min.). 


\subsubsection{Grupo experimental}

Além de participarem do mesmo programa de exercícios físicos do que os integrantes do grupo controle, os sujeitos realizaram um treinamento na plataforma de vibração Power Plate®, com exercícios isométricos, duas vezes pro semana, durante 13 semanas. Os exercícios foram: agachamentos com os pés paralelos, joelhos flexionados entre 110 e $130^{\circ}$ (angulação mais confortável) e flexão do quadril de aproximadamente $140^{\circ}$ (angulação mais confortável); agachamento com os pés voltados para fora e agachamento unilateral com os mesmos graus de flexão de joelho e quadril. O aumento na intensidade dos exercícios foi através do aumento no número de séries, na amplitude de vibração ou na intensidade da vibração. Até a $16^{\mathrm{a}}$ sessão a amplitude foi baixa $(2-4 \mathrm{~mm})$ e da $17^{\mathrm{a}}$ até o final a amplitude alta (4-6mm). Utilizouse uma freqüência de $30 \mathrm{~Hz}$ nas oito primeiras sessões, de $35 \mathrm{~Hz}$ da nona sessão até a $16^{\mathrm{a}}$ sessão e de $40 \mathrm{~Hz}$ a partir da $17^{\mathrm{a}}$ sessão até o final do estudo.

Nas quatro primeiras sessões foram feitas duas séries de trinta segundos de agachamento. Durante as quatro sessões seguintes, três séries de agachamento com duração de 30 segundos. Da nona até a $12^{\mathrm{a}}$ sessão foram feitos agachamento e agachamento com os pés voltados para fora, da $13^{\mathrm{a}}$ até o final incluiu-se o agachamento unilateral. $\mathrm{O}$ número de séries e a duração das séries estão descritos na TABELA 2. As sessões tiveram duração máxima de 20 minutos, incluindo aquecimento e alongamento.

\subsection{Avaliações}

As avaliações foram realizadas em duas sessões, tanto no pré quanto no pós-teste. Na primeira sessão realizaram-se as medidas antropométricas e uma bateria de testes funcional para avaliar as atividades da vida diária, desenvolvida para avaliar força muscular de membros inferiores e superiores, flexibilidade de membros superiores e inferiores, agilidade, equilíbrio dinâmico e resistência aeróbia. Já na segunda sessão foi avaliado o pico de torque e a potência média obtida em um dinamômetro isocinético.

\subsubsection{Medidas antropométricas (estatura, massa corporal e índice de massa corporal):}


A medida da estatura foi realizada em um estadiômetro com escala de $0,1 \mathrm{~cm}$ e a de massa corporal total em uma balança eletrônica da marca Filizola ${ }^{\circledR}$ com $0,1 \mathrm{~kg}$ de precisão. O índice de massa corporal $(\mathrm{IMC})$ foi calculado através da fórmula massa corporal•estatura ${ }^{-2}\left(\mathrm{~kg} \bullet \mathrm{m}^{-2}\right)$.

\subsubsection{Flexibilidade (chair sit-and reach):}

Sentar na Cadeira e Alcançar (SCA) - O sujeito sentou na beira da cadeira, com uma perna estendida o máximo possível e tornozelo em posição neutra $\left(90^{\circ}\right)$ e desceu lentamente o tronco com os cotovelos estendidos e as mãos sobrepostas. A outra perna tinha o joelho flexionado a aproximadamente $90^{\circ}$. O final da sola dos pés correspondeu ao ponto zero. Alcançando acima desse ponto, o resultado era negativo, e abaixo, o resultado era positivo. Foram realizadas duas tentativas, e o melhor escore utilizado.

\subsubsection{Agilidade (8ft up-and-go):}

Levantar, ir e voltar (LIV) - O sujeito inicia o teste sentado em uma cadeira, mãos nas coxas e pés apoiados no solo. Ao sinal do avaliador, o sujeito deveria levantar e caminhar o mais rápido possível, passar por trás de um cone a uma distância de 2,44 m e retornar à posição inicial. O tempo começa a ser contado a partir do sinal do avaliador e termina quando o sujeito senta na cadeira. Após a demonstração, o sujeito realizava uma tentativa do teste e logo após, eram realizadas duas tentativas, e utilizamos o melhor escore (tempo em segundos).

\subsubsection{Flexibilidade (back scratch):}

Mãos nas Costas (MC) - Em pé, o sujeito colocava sua mão de preferência nas costas, passando o braço por sobre o ombro. A palma da mão devia estar voltada para as costas com os dedos estendidos, tentando alcançar a maior distância (em direção aos quadris). A outra mão também devia ser colocada nas costas, porém com o braço passando pela lateral do corpo. $\mathrm{O}$ objetivo do teste era aproximar (ou sobrepor) as mãos o máximo possível. Após demonstração do avaliador, o sujeito tinha duas tentativas e, como resultado, utilizamos o melhor escore. A medida da distância entre os dedos médios era feita em $\mathrm{cm}$. Um escore negativo foi dado quando os dedos não conseguiam se tocar e positivo quando os dedos se sobrepunham. 
Tabela 2. Progressão do programa de exercícios do TV durante as 26 sessões

\begin{tabular}{|c|c|c|c|c|}
\hline Exercício & $\begin{array}{c}\text { Freqüência } \\
(\mathbf{H z})\end{array}$ & $\begin{array}{c}\mathbf{n}^{\circ} \\
\text { séries }\end{array}$ & $\begin{array}{c}\text { Duração } \\
(\mathbf{s})\end{array}$ & Sessões \\
\hline Agachamento & 30 & 2 & 30 & $1^{\mathrm{a}} \mathrm{a} 4^{\mathrm{a}}$ \\
\hline Agachamento & 30 & 3 & 30 & $5^{a}$ a $8^{a}$ \\
\hline Agachamento & 35 & 3 & 45 & $9^{\mathrm{a}}$ a $10^{\mathrm{a}}$ \\
\hline $\begin{array}{c}\text { Agachamento (pes voltados para } \\
\text { fora) }\end{array}$ & 35 & 1 & 30 & $9^{\mathrm{a}}$ a $10^{\mathrm{a}}$ \\
\hline Agachamento & 35 & 3 & 45 & $11^{\mathrm{a}}$ a $12^{\mathrm{a}}$ \\
\hline $\begin{array}{c}\text { Agachamento (pes voltados para } \\
\text { fora) }\end{array}$ & 35 & 2 & 30 & $11^{\mathrm{a}} \mathrm{a} 12^{\mathrm{a}}$ \\
\hline $\begin{array}{c}\text { Agachamento } \\
\text { Agachamento (pes voltados para }\end{array}$ & 35 & 3 & 45 & $13^{\mathrm{a}}$ a $16^{\mathrm{a}}$ \\
\hline fora) & 35 & 2 & 30 & $13^{\mathrm{a}}$ a $16^{\mathrm{a}}$ \\
\hline Agachamento unilateral & 35 & 1 & 30 & $13^{\mathrm{a}}$ a $16^{\mathrm{a}}$ \\
\hline $\begin{array}{c}\text { Agachamento } \\
\text { Agachamento (pés voltados para }\end{array}$ & 40 & 3 & 45 & $17^{\mathrm{a}}$ a $20^{\mathrm{a}}$ \\
\hline fora) & 40 & 2 & 45 & $17^{\mathrm{a}}$ a $20^{\mathrm{a}}$ \\
\hline Agachamento unilateral & 40 & 1 & 30 & $17^{\mathrm{a}}$ a $20^{\mathrm{a}}$ \\
\hline $\begin{array}{c}\text { Agachamento } \\
\text { Agachamento (pés voltados para }\end{array}$ & 40 & 3 & 45 & $21^{\mathrm{a}}$ a $23^{\mathrm{a}}$ \\
\hline fora) & 40 & 2 & 45 & $21^{\mathrm{a}}$ a $23^{\mathrm{a}}$ \\
\hline Agachamento unilateral & 40 & 1 & 30 & $21^{\mathrm{a}}$ a $23^{\mathrm{a}}$ \\
\hline $\begin{array}{c}\text { Agachamento } \\
\text { Agachamento (pés voltados para }\end{array}$ & 40 & 3 & 60 & $24^{\mathrm{a}}$ a $26^{\mathrm{a}}$ \\
\hline fora) & 40 & 2 & 45 & $24^{\mathrm{a}}$ a $26^{\mathrm{a}}$ \\
\hline Agachamento unilateral & 40 & 1 & 30 & $24^{\mathrm{a}}$ a $26^{\mathrm{a}}$ \\
\hline
\end{tabular}

\subsubsection{Força de membros inferiores (chair standing):}

Sentar e Levantar (SL) - O teste iniciava com o sujeito sentado com as costas encostadas na cadeira e os pés apoiados no chão. Ao sinal do avaliador, o sujeito devia levantar e voltar à posição inicial. O sujeito foi encorajado a completar o maior número de repetições possível no período de 30 segundos. Antes de iniciar o teste o avaliador demonstrava o exercício e então o sujeito praticava de uma a três repetições para aprendizagem do movimento, iniciando o teste em seguida, realizando uma única tentativa. 


\subsubsection{Força de membros superiores (arm curl):}

Flexão de Cotovelo (FC) - O sujeito estava na posição sentada com as costas apoiada na cadeira, executava o movimento de flexão e extensão dos cotovelos do membro dominante (Carga: 5 libras para mulheres e 8 libras para homens). O teste iniciava com o braço estendido e ao sinal do avaliador o sujeito flexionava e estendia o cotovelo. O sujeito era encorajado a completar o maior número de repetições possível no período de 30 segundos. Após demonstração do teste, o sujeito praticava de uma a três repetições para aprendizagem do movimento, iniciando o teste em seguida, realizando uma única tentativa.

\subsubsection{Resistência aeróbia (6 min walk):}

Caminhada 6 min (C6M) - Distância percorrida, caminhando, em um período de 6 minutos. O percurso retangular tinha uma distância total de 45,72m e foi demarcado a cada 4,57m. Os sujeitos eram avisados quando faltavam 2 minutos e 1 minuto para o término do tempo. Ao final do tempo, os sujeitos paravam onde estavam e então, era feita a medida da distância percorrida.

\subsubsection{Força e potência muscular:}

Foram realizadas avaliações no dinamômetro Isocinético, modelo Rev 9000 da Technogym®. O teste foi composto de duas séries, sendo uma série de cinco repetições a $60^{\circ}$ /s e uma série de 5 repetições a 180\% (com objetivo de mensurar força e potência), com intervalo de 90 segundos entre as séries. Os sujeitos eram encorajados a realizar o máximo de força de extensão de joelho do membro dominante. A força máxima e a potência média realizadas foram medidas a cada repetição e foram utilizados os melhores resultados obtidos em cada série para análise.

Primeiramente, os sujeitos realizavam um aquecimento no ciclo ergômetro com carga de 25 watts, com duração de cinco minutos e uma sequiência de exercícios de alongamento de quadríceps por mais cinco minutos. Após, os sujeitos realizaram um aquecimento específico que era constituído de duas séries de cinco repetições com as mesmas velocidades dos testes para se 
familiarizarem ao tipo de resistência oferecida pelo dinamômetro, durante essas séries os sujeitos foram orientados a não realizar força máxima.

\subsection{Análise estatística}

Para cada variável dependente foi usado um modelo misto tendo o tratamento (treino na plataforma vibratória e controle) e o momento (pré e pós) como fatores fixos e sujeitos como fator aleatório. No caso de valores de F significantes, comparações múltiplas foram realizadas com ajustamento de Tukey. O nível de significância foi fixado em $\mathrm{p}<0,05$.

\section{RESULTADOS}

O treinamento na plataforma vibratória não foi efetivo em melhorar o desempenho nos testes funcionais em idosos. Contudo, o programa de exercícios físicos ao que os sujeitos de ambos os grupos participaram foi eficiente em aumentar a força dos flexores de cotovelo e a distância percorrida no teste de caminhada de 6 minutos e diminuir o tempo para cumprir o percurso no teste de agilidade/equilíbrio ( $\mathrm{p}<0,05$, TABELA 3).

O modelo de treinamento vibratório utilizado não foi eficiente em aumentar tanto o torque quanto a potência dos músculos extensores do joelho. Além disso, o programa de exercício físico utilizado também não produziu melhoras nas variáveis descritas abaixo (TABELA 4)

\section{DISCUSSÃO}

O programa de exercícios físicos foi eficiente em aumentar a resistência de força dos flexores do cotovelo, a velocidade no teste de agilidade/equilíbrio e a distância percorrida no teste de caminhada de 6 minutos em indivíduos fisicamente ativos. Tanto o treinamento na plataforma vibratória quanto o programa de exercícios físicos não foram eficientes em aumentar o torque e a potência dos músculos extensores do joelho.

O teste de agilidade/equilíbrio (LIV) envolve potência, velocidade, agilidade e equilíbrio dinâmico (RIKLI \& JONES, 1999), capacidades físicas que declinam com o envelhecimento, 
aumentando o risco não só de quedas e fraturas, como também diminuindo o nível de independência do idoso. Esperávamos que o TV melhorasse o desempenho dos idosos nesse teste. No entanto, nossos resultados diferem de achados anteriores (BAUTMANS et al., 2005; BRUYERE et al., 2005; KAWANABE et al., 2007).

Os estudos de BAUTMANS et al. (2005) e BRUYERE et al. (2005) reportaram melhora no desempenho no teste de LIV após o treinamento vibratório de 21,6\% e 30,5\%, respectivamente. Um ponto importante é que ambos os estudos encontraram melhora no teste de Tinetti (equilíbrio) e atribuíram o aumento de desempenho no LIV à melhora no equilíbrio, já que não encontraram aumentos significantes de força e potência muscular, o que também justificaria a melhora no desempenho. A ausência de ganho na força e potência muscular após o TV em nosso estudo, indicada pela manutenção nos valores de pico de torque e de potência média no teste isocinético, pode ser então a razão pelo qual não vimos mudanças no teste LIV. Os estudos citados utilizaram um modelo de TV com características semelhantes a esse $(26-50 \mathrm{~Hz}, 2-7 \mathrm{~mm}$, 240 a 400 s de exposição à vibração por sessão), tiveram a mesma duração (seis semanas - 18 sessões). Contudo, os autores não descreveram o nível de condicionamento físico inicial dos sujeitos. Dessa forma, apesar da diferença na distância percorrida $(2,44 \mathrm{~m}$ e 3,0m), seus resultados no teste de ir e voltar (15,3 e 36,1s), comparados com o resultado do presente estudo (5,2s), sugerem que os sujeitos dos estudos de BAUTMANS et al. (2005) e BRUYERE et al. (2005) eram muito debilitados (BISCHOFF, STÄHELIN, MONSCH, IVERSEN, WEYH, DECHEND, AKOS, CONZELMANN, DICK \& THEILER, 2003; SHUMWAY-COOK, BRAUER \& WOOLLACOTT, 2000), o que pode ser um fator relevante para a melhora encontrada no desempenho.

Outros estudos avaliaram o efeito do TV no equilíbrio utilizando outros métodos de avaliação (variações de testes em plataformas de equilíbrio) e também encontraram melhora no desempenho com o TV (BOGAERTS et al., 2007 e KAWANABE et al., 2005). No entanto, esses estudos não realizaram o teste de LIV, o que torna difícil a comparação. 


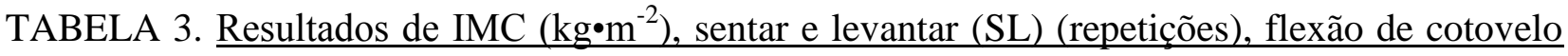
(FC) (repetições), Sentar na cadeira e Alcançar (SCA) (cm), Mãos nas Costas (MC) (distância cm), Agilidade (segundos), Caminhada 6 minutos (C6m) (distância - metros) nos grupos de treinamento vibratório (TV) e grupo controle (GC) pré- e pós treinamento (média \pm desvio padrão)

\begin{tabular}{lllll}
\hline & \multicolumn{3}{l}{ Grupo TV } & \multicolumn{2}{l}{ Grupo Controle } \\
\hline IMC & Pré-teste & Pós-teste & Pré-teste & Pós-teste \\
\cline { 2 - 5 } SL & $25,7 \pm 4,2$ & $25,3 \pm 3,7$ & $26,2 \pm 3,6$ & $26,6 \pm 3,8$ \\
FC* & $20,0 \pm 3,7$ & $19,8 \pm 3,0$ & $17,5 \pm 3,8$ & $16,9 \pm 4,9$ \\
SCA & $21,7 \pm 3,7$ & $25,2 \pm 3,4$ & $19,6 \pm 4,3$ & $21,9 \pm 4,9$ \\
MC & $3,3 \pm 9,8$ & $5,6 \pm 13,6$ & $4,9 \pm 11,1$ & $3,6 \pm 13,9$ \\
Agilidade* & $-4,1 \pm 9,2$ & $-4,3 \pm 9,2$ & $-3,6 \pm 10,3$ & $-5,4 \pm 11,2$ \\
C6M* & $5,2 \pm 0,6$ & $4,8 \pm 0,5$ & $5,5 \pm 1,2$ & $5,3 \pm 1,2$ \\
\hline$*$
\end{tabular}

*Efeito principal de tempo $(\mathrm{p}<0,05)$

TABELA 4. Resultados de Pico de Torque $60^{\circ} \cdot \mathrm{s}^{-1}$ (Watt), Potência média $60^{\circ} \cdot \mathrm{s}^{-1}$ (Watt), Pico de Torque $180^{\circ} \cdot \mathrm{s}^{-1}$ (Watt), Potência média $180^{\circ} \cdot \mathrm{s}^{-1}$ (Watt) nos grupos de treinamento vibratório (TV) e grupo controle (GC) pré- e pós treinamento (média \pm desvio padrão).

\begin{tabular}{lllll}
\hline \multicolumn{3}{l}{ Grupo TV } & \multicolumn{2}{l}{ Grupo Controle } \\
\hline & Pré-teste & Pós-teste & Pré-teste & Pós-teste \\
\cline { 2 - 5 } Pico de Torque $60^{\circ} \cdot \mathrm{s}^{-1}$ & $85,3 \pm 34,5$ & $86,3 \pm 39,7$ & $88,0 \pm 37,6$ & $99,0 \pm 20,0$ \\
Potência média $60^{\circ} \cdot \mathrm{s}^{-1}$ & $52,0 \pm 41,4$ & $57,2 \pm 32,9$ & $55,3 \pm 30,5$ & $58,7 \pm 11,4$ \\
Pico de Torque $180^{\circ} \cdot \mathrm{s}^{-1}$ & $64,6 \pm 26,5$ & $66,0 \pm 32,1$ & $67,3 \pm 22,1$ & $69,0 \pm 10,1$ \\
Potência média $180^{\circ} \cdot \mathrm{s}^{-1}$ & $69,2 \pm 37,0$ & $88,2 \pm 60,4$ & $104,6 \pm 99,4$ & $86 \pm 31,0$ \\
\hline
\end{tabular}

Não houve aumento significativo na flexibilidade, tanto para membros superiores como inferiores, em nenhum dos grupos, resultados semelhantes aos encontrados por BAUTMANS et 
al. (2005), que utilizou os mesmos protocolos de avaliação. Contudo, o estudo de FAGNANI, F., GIOMBINI, DI CESARE, PIGOZZI e DI SALVO, (2006) reportou melhora na flexibilidade (13\%), medida no teste de sentar e alcançar, em mulheres atletas (de 21 a 27 anos) após oito semanas de TV. As sobrecargas eram semelhantes (frequiência $35 \mathrm{~Hz}$, amplitude $(4 \mathrm{~mm})$, e somente o peso corporal, sem sobrecarga adicional, iniciando com 3 séries de 20s e no final do estudo, 4 séries de 60s para agachamento, e 4 séries de 30s para agachamento unilateral), porém os treinos eram realizados 3 vezes por semana, durante 8 semanas. Da mesma forma, o estudo de ISSURIN, LIEBERMANN \& TENEBAUM (1994) reportou um aumento de 43,6\% no mesmo teste com a utilização de vibração direta em atletas que treinaram três vezes por semana durante três semanas. ISSURIN et al. (1994) e FAGNANI et al (2006) sugerem que essa melhora pode acontecer em função do aumento do limiar de dor, bem conhecido como barreira natural para a flexibilidade e também por um aumento da temperatura e do fluxo sanguíneo. E que o TV produz um efeito analgésico durante e após a vibração. Outro mecanismo é baseado na excitação do órgão tendinoso de golgi (OTG), que inibi a contração, seguido pelo relaxamento do músculo. Talvez essa melhora na flexibilidade em atletas possa ser atribuída ao treinamento específico de suas modalidades esportivas e não ao TV, ou também ao efeito da vibração direta (ISSURIN et al., 1994) que parece ser mais eficiente em estimular os mecanismos citados acima. Atletas apresentam uma treinabilidade menor do que a de idoso e por isso não deveriam melhorar a flexibilidade, enquanto que se o TV produzisse melhorias nessa capacidade os idosos deveriam apresentar.

O que difere da grande maioria dos estudos com idosos (ROELANTS et al., 2004, RUSSO et al., 2003, VERSCHUEREN et al., 2004) e também em estudos com jovens (DELECLUSE et al., 2003, RONNESTAD, 2004) são as variáveis força e potência musculares, que não encontramos melhora após o período de treinamento.

O número de sessões, intensidade, tempo de exposição à vibração e exercícios realizados na plataforma são fatores importantes a ser considerados nessa análise. Os exercícios utilizados nos estudos eram semelhantes (variações de agachamento). Com isso, as diferenças entre os estudos parecem estar relacionadas às características do protocolo de TV ou às características dos sujeitos. 
Os estudos que encontraram aumento na força dinâmica apresentam uma frequiência de vibração semelhante (35-40 Hz), o que difere os estudos é a amplitude da vibração e o número de sessões de treinamento. Em relação ao primeiro fator, no estudo de VERSCHUEREN et al. (2004) foi utilizada uma amplitude de 1,7 - 2,5 mm e nos de ROELANTS et al. (2004) de 2- 5,5 $\mathrm{mm}$, obtendo ganhos de $15 \%$ na força isométrica e $16,5 \%$ na força dinâmica dos extensores do joelho e de $12,4 \%$ e $12,1 \%$ para as mesmas variáveis, respectivamente. Dessa forma, a amplitude do treino vibratório não parece ter efeito sobre a magnitude das adaptações. Em relação ao segundo fator, VERSCHUEREN et al. (2004) e ROELANTS et al. (2004) utilizaram 72 sessões de treinamento de vibração, porém o percentual de aumento reportado no último estudo foi obtido com apenas 36 sessões de TV. Esses dados indicam que o número de sessões também não é um fator determinante na magnitude das adaptações encontradas. $\mathrm{O}$ único fator que poderia explicar as diferenças em ganhos de força entre o nosso estudo e os citados é a característica da amostra já que eles utilizaram idosos sedentários enquanto nós utilizados idosos fisicamente ativos.

ROELANTS et al (2005) encontraram, também, melhora no desempenho do salto vertical com contra movimento para o grupo TV (19,4\%). RUSSO et al (2003) encontraram melhora no salto vertical (5\%) para o TV após 24 semanas de treinamento (2x semana, iniciando com 3x 1 min e no final do estudo 3x 2 min; a freqüência de 12 para 28Hz). No presente estudo não foi encontrado aumento na potência média nos testes isocinéticos. A diferente natureza dos testes (altura do salto vertical e potência média no isocinético) pode ter induzido a ausência de ganhos de potência no nosso estudo devido a baixa sensibilidade do teste isocinético.

Quanto ao aumento na força de flexores do cotovelo que apresentaram efeito de tempo, o que demonstra que apenas o programa de exercício físico foi eficiente para a melhora dessas variáveis. Isso pode ter ocorrido em função da utilização de exercícios de força para membros superiores no programa de exercício físico, já que esse grupo muscular não foi treinado no nosso programa de TV.

Houve um efeito de tempo na distância percorrida no teste de 6 minutos, o que mostra que o programa de exercício físico foi o responsável por esse aumento. Esse aumento é importante para melhora da qualidade de vida do idoso, considerando que esse teste vem sendo relacionado com desempenho funcional e, que os idosos necessitam de um adequado nível de desempenho 
aeróbio para algumas atividades diárias, como caminhada, deslocamento dentro de casa, passeio ao shopping e até mesmo o ato de ir ao banheiro (RIKLI \& JONES, 1999; SHEPHARD, 1993). Como o teste está relacionado ao desempenho aeróbio, o treinamento específico, aeróbio, realizado nas sessões de treinamento pelos dois grupos parece justificar essa melhora.

\section{CONCLUSÃO}

Os resultados sugerem que TV realizado durante 13 semanas (26 sessões) parece não ser eficiente para modificar o desempenho em testes funcionais em idosos fisicamente ativos. Enquanto o treinamento físico se mostrou eficiente para melhora das variáveis de força dos flexores de cotovelo, distância percorrida no teste de 6 minutos e no teste de agilidade. E ambos os treinamentos não demonstraram ser eficientes para aumentar o pico de torque e a potência média dos músculos extensores do joelho. 


\section{REFERÊNCIAS}

AKATAKI, K., MITA, K., WATAKABE, M., ITO, K. Age related change in motor unit activation strategy in force production: a mechanomyographic investigation Muscle \& Nerve, New York, 25:505-512, 2002.

AOYAGI, Y; SHEPHARD, R.J. Aging and muscle function. Sports Medicine, Auckland, v.14, n.6, p.376-396, 1992.

BAUTMANS, I.; VAN HEES, E.; LEMPER, J.C.; METS, T. The feasibility of Whole Body Vibration in institutionalized elderly persons and its influence on muscle performance, balance and mobility: a randomized controlled trial. BMC Geriatrics, London. v.5, n.17, 2005.

BISCHOFF, H.A.; STÄHELIN, H.A.; MONSCH, A.U.; IVERSEN, M.D.; WEY, A.; DECHEND, M.V.; AKOS, R.; CONZELMANN, M.; DICK, W.; THEILER, R. Identifying a cutoff point for normal mobility: a comparison of the timed 'up and go' test in community-dwelling and institutionalised elderly women. Age and Ageing, London, v.32, n.3, p.315-320, 2003.

BOSCO, C.; CARDINALE, M.; et al. New trends in training science: The use of vibration for enhancing performance. New Studies in Athletics, Aachen, v.14, n.4, p.55-62, 1999.

BRUYERE, O.; WUIDART, M. A.; DI PALMA, E.; GOURLAY, M.; ETHGEN, O.; RICHY, F.; REGINSTER, J. Y. Controlled whole body vibration to decrease fall risk and improve healthrelated quality of life of nursing home residents. Archives Physical Medicine Rehabilitation, Chicago, v.86, p.303-307, 2005.

BROOKS, G.A.; FAHEY, T.D. Aging. In: Exercise Physiology and Human Bioenergetics and its Applications. Chapter 31, New York: ed. Interamericanas, 1983.

CARDINALE, M.; BOSCO, C. The use of vibration as an exercise intervention. Exercise and Sport Science Reviews, Baltimore, v.31, p. 3-7, 2003.

COCHRANE, D. J.; STANNARD, S. R. Acute whole body vibration training increases vertical jump and flexibility performance in elite female field hockey players. British Journal of Sports Medicine. London, v.39, p. 860-865, 2005. 
DELECLUSE, C.; ROELANTS, M.; VERSCHUEREN, S. Strength increase after whole-body vibration compared with resistance training. Medicine and Science Sports and Exercise, Madison, v.35, p. 1033-1041, 2003.

FAGNANI, F.; GIOMBINI, A.; DI CESARE, A.; PIGOZZI, F.; DI SALVO, V. The effects of whole-body vibration program on muscle performance and flexibility in female athletes. American Journal of Medicine and Rehabilitation, v. 85, n.12, p.956-962, 2006.

FIATARONE, M.A.; O’NEIL, E.F.; RYAN, N.D.; CLEMENTS, K.M.; SOLARES, G.R.; NELSON, M.E.; ROBERTS, S.B.; KEHAYIAS, J.J.; LIPSITZ, L.A.; EVANS, W.J. Exercise training and nutritional supplementation for physical frailty in very elderly people. New England Journal of Medicine, Waltham, v.330, p. 1769-1775, 1994.

FIATARONE, M.A.; MARKS, E.C.; RYAN, N.D.; MEREDITH, C.N.; LIPSITZ, L.A.; EVANS, W.J. High-intensity strength training in nonagenarians. Journal of the American Medical Association, Chicago, v.263, n.22, p.3029-3034, 1990.

FRONTERA, W.R.; BIGARD, X. The benefits of strength training in the elderly. Science \& Sports, London, v. 17, p. 109-116, 2002.

FRONTERA, W.R.; MEREDITH, C.N.; O’REILLY, K.P.; KNUTTGEN, H.G.; EVANS, W.J. Strength conditioning in older men: skeletal muscle hypertrophy and improved function. Journal Applied Physiology, Bethesda, v.64, n.3, p.1038-1044, 1988.

FUNDAÇÃO INSTITUTO BRASILEIRO DE GEOGRAFIA E ESTATÍSTICA. Diretoria de Pesquisas, Censos Demográficos, IBGE. Brasília; 2000. Disponível em http://www.ibge.gov.br GROSS, M.M.; STEVENSON, P.J.; CHARETTE, S.L.; PYKA, G.; MARCUS, R. Effect of muscle strength and movement speed on the biomechanics of rising from a chair in healthy elderly and young women. Gait Posture, Oxford, v.8, n.3, p.175-185, 1998.

HAWKINS. A.L.; EKLUND, S.J.; JINGYI, Y. Cross-cultural comparisons of the daily activity patterns and life satisfactions of older adults in Chine, Australia and United States. Journal of Cross-Cultural Psychology, Dellingham, v.4, p.4-10, 1998. 
ISSURIN, V.B.; LIEBERMANN, D.G.; TENEBAUM, G. Effect of vibratory stimulation training on maximal force and flexibility. Journal of Sports Sciences, London, v.12, p.561-566, 1994. IZQUERDO, M.; HAKKINEN, K.; ANTÓN, A.; GARRUES, M.; IBAÑEZ, J.; RUESTA, M.; GOROSTIAGA, M.E. Maximal strength and power, endurance performance, and serum hormones in middle-aged and elderly men. Medicine and Science in Sports and Exercise, Madison, v.33, n.9, p.1577-87. 2001.

JORDAN, M. J.; NORRIS, S. R.; SMITH, D. J.; HERZOG, W. Vibration training: an overview of the area, training consequences, and future considerations. Journal of Strength and Conditioning Research, Champaign, v.19, p.459-466, 2005.

KAWANABE, K.; KAWASHIMA, A.; SASHIMOTO, I.; TAKEDA, T.; SATO, Y.; IWAMOTO, J. Effect of whole-body vibration exercise and muscle strengthening, balance, and walking exercises on walking ability in the elderly. Journal of Medicine, Westbury, v.56, n.1, p. 28-33, 2007.

LARSSON, L. Histochemical characteristics of human skeletal muscle during aging. Acta Physiologica Scandinavica, Stockholm, v.117, p.469-471, 1983.

LUO, J.B.; MCNAMARA, C.; MORAN, K. The use of vibration training to enhance muscle strength and power. Sports Medicine, Auckland, v.35, p.23-41, 2005.

MATTIELO-SVERZUT, A.C. Histopatologia do músculo esquelético no processo de envelhecimento e fundamentação para a prática terapêutica de exercícios físicos e prevenção da sarcopenia. Revista de Fisioterapia da Universidade de São Paulo, São Paulo, v.10, n. 1, p. 24$33,2003$.

MAZZEO, R.S., CAVANAGH, P., EVANS, W.J., FIATARONE, M., HAGBERG, J., McAUlEY, E., STARTZELL, J. ACSM Position: xercise and Physical Activity for Older Adults. Medicine Science Sports Exercise, Madison, v. 30, n. 6, p. 992-1008, 1998.

MISZKO, T.A.; CRESS, M.E.; SLADE, J.M.; COVEY, C.J.; AGRAWAL, S.K.; DOER, C.E. Effect of strength and power training on physical function in community-dwelling older adults. 
The Journals of Gerontology Series A: Biological Sciences and Medical Sciences. v.58A, p. 171-175, 2003.

MOTA, J. Envelhecimento e exercício - atividade física e qualidade de vida na população idosa. In: BARBANTI, V.J.; AMADIO, A.C.; BENTO, J.O.; MARQUES, A.T. Orgs., Esporte e Saúde: interação entre rendimento e qualidade de vida. São Paulo: ed. Manole, 2002. p. 183-194.

OKUMA, S.S. O Idoso e a Atividade Física: fundamentos e pesquisa. Campinas: ed. Papirus, 2 ed, 1998.

POWERS, K.S.; HOWLEY, E.T. Fisiologia do Exercício - teoria e aplicação ao condicionamento e ao desempenho - cap. 17, 3ª ed. pág. 311-12. 2000.

RAMOS, R. L.; ROSA, T. E. C.; et al. Profile of the elderly in an metropolitan area of Southeastern Brazil: results of a household survey. Revista de Saúde Pública, São Paulo, v.27, n.2, p.87-94. 1993.

REEVES, N.D.; MAGNANARIS, C.N.; NARICI, M.V. Ultrasonographic assessment of human skeletal muscle size. European Journal of Applied Physiology. Berlin, v.91, p.116-118, 2004.

RIKLI, R.; JONES, J. Development and validation of a functional fitness test for communityresiding older adults. Journal of Aging and Physical Activity, Champaign, v.7, p.129-161, 1999 RITTWEGER, J., EHRIG, J., JUST, K., MUTSCHELKNAUS, M., KIRSCH, K.A. \& FELSENBERG, D. Oxygen Uptake in Whole-Body Vibration Exercise: Influence of vibration frequency, amplitude, and external load. International Journal Sports Medicine, Stuttgart, v. 23, p.428-432, 2002.

RITTWEGER, J.; MUTSCHELKNAUSS, M.; et al. Acute changes in neuromuscular excitability after exhaustive whole body vibration exercise as compared to exhaustion by squatting exercise. Clinical Physiological Functional Imaging, v.23, n.2, p.81-6. 2003.

ROELANTS, M., C.; DELECLUSE, C.; VERSCHUEREN, S. M. Whole-body-vibration training increases knee-extension strength and speed of movement in older women. Journal of American Geriatric Society. v.52, p.901-908, 2004. 
ROUBENOFF, R. Sarcopenia and its implications for the elderly. European Journal of Clinical Nutrition, Basingstoke, v.54, p.S40-S47, 2000.

RONNESTAD, B. R. Comparing the performance-enhancing effects of squats on a vibration platform with conventional squats in recreationally resistance-trained men. Journal of Strength and Conditioning Research, Champaign, v.18, p.839-845, 2004.

RUSSO, C.R.; LAURETANI, F.; BANDINELLI, S.; BARTALI, B.; CAVAZZINI, C.; GURALNIK, J.M.; FERRUCCI, L. High-frequency vibration training increases muscle Power in postmenopausal women. Archives of Physical Medicine and Rehabilitation, Chicago, v.84, n.11, p.12, p.1854-1857, 2003.

SANTOS, S. Envelhecimento e deficiência: uma análise conceitual. In: Simpósio paulista de educação física adaptada. 3. São Paulo. Anais Simpósio Paulista de Educação Física Adaptada. 1990 , p. 41.

SERRÃO, J.C.; AMADIO, A.C. Análise de características dinâmicas do andar em idosos e sua influência na seleção de atividades física. Proccedings of the First Conference of European Group for Research into Elderly and Physical Activity. Portugal, p.438-441. 1994.

SHEPHARD, R.J. Aging, Physical Activity, and Health. Champaign: Human Kinetics. p. 31-56. 1997.

SHMWAY-COOK, A.; BRAUER, S.; WOOLACOTT, M. Predicting the probability for falls in community-dwelling older adults using the timed up \&go test. Physical Therpy, Chicago, v.80, n.9, p.896-903, 2000.

SIPILA, S.; KOSKINEN, S. O.; et al. Determinants of lower-body muscle power in early postmenopausal women. Journal of American Geriatric Society, v.52, n.6, p.939-44. 2004.

SPIRDUSO, W.W. Muscular Strength and Endurance. In: Physical Dimensions of Aging. Chapter 5, Champaign, Illinois: Human Kinetics Publishers, 1995.

TORVINEN, S., P.; KANNU, H.; SIEVANEN, T. A.; JARVINEN, M.; PASANEN, S.; KONTULAINEN, T. L.; JARVINEN, M.; JARVINEN, P. O.; VUORI, I. Effect of a vibration 
exposure on muscular performance and body balance. randomized cross-over study. Clinical Physiological Functioning Imaging. v.22, p.145-152, 2002.

VERSCHUEREN, S. M.; ROELANTS, M.; DELECLUSE, C.; SWINNEN, S.; VANDERSCHUEREN, D.; BOONEN, S. Effect of 6-month whole body vibration training on hip density, muscle strength, and postural control in postmenopausal women: a randomized controlled pilot study. Journal of Bone Mineral Research, v.19, p.352-359, 2004.

VICENT, K. R.; BRAITH, W.; et al. Resistance exercise and physical performance in adults aged 60 to 83. Journal of American Geriatric Society, v.50, n.6, p.1100-1107. 2002.

WILMORE, J.H., COSTILL, D.L. Adaptações neuromusculares ao treinamento de força. In: Fisiologia do Esporte e do Exercício. Capítulo 3, São Paulo: ed. Manole, 2001.

WINTER, D.A.; PATIA, A.E.; FRANK, J.S.; WALT, S.R. Biomechanical walking pattern changes in the fit and healthy elderly. Physical Therapy, Chicago, v.70, n.6, p. 340-347, 1990. 